\title{
Early breast development in overweight girls: does estrogen made by adipose tissue play a role?
}

\author{
Lauren Carlson ${ }^{\star}{ }^{1}$, Vanessa Flores ${ }^{\star}, 1$, Bob Z. Sun ${ }^{1}$, Brittany Mosley ${ }^{1}$, Imke Kirste ${ }^{1}$, Annette \\ Rice $^{1}$, Rithi Sridhar ${ }^{1}$, Tairmae Kangarloo ${ }^{2}$, Hubert W Vesper ${ }^{3}$, Lumi Duke ${ }^{3}$, Julianne C \\ Botelho $^{3}$, Armando C Filie ${ }^{4}$, Judy M Adams ${ }^{2}$, Natalie D. Shaw ${ }^{1,2}$ \\ ${ }^{1}$ Clinical Research Branch, National Institutes of Environmental Health Sciences, National \\ Institutes of Health, Research Triangle Park, NC ${ }^{2}$ Reproductive Endocrine Unit, Massachusetts \\ General Hospital, Boston, MA ${ }^{3}$ Division of Laboratory Sciences, Centers for Disease Control and \\ Prevention, Atlanta, GA ${ }^{4}$ Cytopathology Section, Laboratory of Pathology, Center for Cancer \\ Research, National Cancer Institute, National Institutes of Health, Bethesda, Maryland
}

\section{Abstract}

Background-Girls who are overweight/obese (OB) develop breast tissue but do not undergo menarche (the first menstrual period) significantly earlier than girls of normal weight (NW). It has been proposed that estrogen synthesized by adipose tissue may be contributory, yet OB do not have higher serum estrogen levels than NW matched on breast stage. We hypothesized that estrogen synthesized locally, in mammary fat, may contribute to breast development. This hypothesis would predict that breast development would be more advanced than other estrogensensitive tissues as a function of obesity and body fat.

\begin{abstract}
Methods-80 pre-menarchal girls ( $26 \mathrm{OB}, 54 \mathrm{NW}$ ), aged 8.2-14.7 yrs, underwent dual-energy xray absorptiometry to calculate percent body fat $(\% \mathrm{BF})$, Tanner staging of the breast, breast ultrasound for morphological staging, trans-abdominal pelvic ultrasound, hand x-ray (bone age), a blood test for reproductive hormones, and urine collection to determine the vaginal maturation index (VMI), an index of estrogen exposure in urogenital epithelial cells.
\end{abstract}

Results-When controlling for breast morphological stage determined by ultrasound, \%BF was not associated with serum estrogen or gonadotropin (LH and FSH) levels or on indices of systemic estrogen action (uterine volume, endometrial thickness, bone age advancement, and VMI). Tanner breast stage did not correlate with breast morphological stage and led to misclassification of chest fatty tissue as breast tissue in some OB.

Users may view, print, copy, and download text and data-mine the content in such documents, for the purposes of academic research, subject always to the full Conditions of use:http://www.nature.com/authors/editorial_policies/license.html\#terms

Correspondence: Address all correspondence and requests for reprints to Natalie D. Shaw, MD, MMSc., National Institute of Environmental Health Sciences, 111 TW Alexander Drive, MD A2-03, RTP, NC 27709, Tel +1 984287 3716, Fax +1 3014515539 , Natalie.shaw@nih.gov.

* These authors contributed equally to this work.

Disclosure Summary: The authors have nothing to disclose.

Clinicaltrials.gov registration number: NCT02583646

Supplementary information is available at $I J O$ 's website. 
Conclusions-These studies do not support the hypothesis that estrogen derived from total body fat or local (mammary) fat contributes to breast development in overweight/obese girls.

\section{INTRODUCTION}

The past two centuries have witnessed a dramatic change in the timing of puberty in girls. The average age at menarche fell by nearly 5 years from the early $19^{\text {th }}$ century to the mid- $20^{\text {th }}$ century, most likely reflecting improvements in socioeconomic and health conditions, but by the 1960's, the average age at menarche had stabilized at 12 to 12.5 years $(1,2)$. More recent studies, however, point to an emerging secular trend of earlier breast development (thelarche) in girls. The rapid pace of this change precludes a genetic explanation; instead, the contemporaneous obesity epidemic suggests that obesity may be the primary driver of earlier thelarche (3). Indeed, a number of longitudinal studies (4-7) have now demonstrated earlier thelarche in girls who are overweight/obese (OB) compared with girls of normal weight $(\mathrm{NW})$.

It has long been proposed that in peri-pubertal girls with obesity, estrogen may be derived not from the ovary, but from peripheral adipose tissue which may convert adrenal androgens to estrone (E1) and, to a lesser extent, estradiol (E2), via the aromatase enzyme. The asynchrony of pubertal milestones observed in contemporary girls (earlier thelarche, relatively stable age at menarche) would be consistent with a peripheral trigger. Studies in pubertal pre-menarchal girls, however, have not identified a correlation between body fat mass, quantified by skinfold measurements (8) or dual-energy x-ray absorptiometry (DXA) (9), and serum E1 or E2 nor a decrease in E2 after significant weight loss (10).

We hypothesized that in OB, adipose tissue overlying the breast bud may be a ready source of estrogen that is sufficient to initiate thelarche. The primitive breast bud is intimately associated with the mammary fat pad during development $(11,12)$. Estrogen derived from mammary fat could act locally to induce thelarche but would not be detected in the circulation and therefore would not act systemically to induce uterine maturation and menses. To address this hypothesis, we measured reproductive hormones and imaged the breast, uterus, and ovaries in 80 pubertal, pre-menarchal girls. We used total body fat as determined by DXA as a proxy for mammary fat, taking advantage of the positive correlation between these two measures in studies in women and girls (13-15). We predicted that if estrogen derived from mammary fat contributes to breast maturation, then girls with more body fat (and thus more mammary fat) would demonstrate immaturity of other estrogen-sensitive tissues (e.g. uterus and endometrial lining, vaginal epithelium) compared with girls of the same breast morphological stage with less body fat.

\section{MATERIALS AND METHODS}

\section{Subjects}

Subjects ( $\mathrm{n}=80)$ were 8.2-14.7-year-old healthy pre-menarchal girls with some breast development (per parental report) recruited from the Triangle region of North Carolina. Subjects had no chronic medical conditions, were not taking any medications or supplements known to affect puberty and did not have a history of precocious puberty or 
premature pubarche (defined as breast development or pubic and/or axillary hair before age 8 years, respectively). The study was approved by the National Institute of Environmental Health Sciences (NIEHS) Institutional Review Board. Signed informed assent and consent was obtained from each subject and her parent, respectively.

\section{Protocol}

All study procedures were conducted at the Clinical Research Unit (CRU) of the National Institute of Environmental Health Sciences (NIEHS) or off-site at a private medical imaging facility.

Anthropometrics and Tanner staging-Height and weight were measured using a stadiometer (SECA AccuHite 216) and medical balance beam scale (Healthometer model $402 \mathrm{KL}$ ), respectively. Waist-to-hip ratio was measured according to the NHANES Anthropometry Procedures Manual (16). Breast Tanner stage was assigned by a pediatric endocrinologist (NDS) based on palpation and inspection of the breast (17). To avoid misclassification of overlying adipose tissue as fibroglandular tissue when assigning a Tanner breast stage, the physical examination also included contrasting chest and abdominal fatty tissues by palpation and determining whether there was a palpable depression beneath the nipple surrounded by firm tissue (the "doughnut sign", an indicator of fatty tissue) (18). Areolar maturity, including pigmentation and stippling (19), were recorded.

Blood and urine sampling-A non-fasting blood sample was collected between 8 am and $4 \mathrm{pm}$ to measure reproductive hormones. Blood samples were available in all but seven participants ( $3 \mathrm{NW}, 4 \mathrm{OB}$ ). Gonadotropins were measured by direct immunoassay using the automated Abbott ARCHITECT system (Abbott Diagnostics, USA) which has a limit of quantification of 0.06 and $0.05 \mathrm{IU} / \mathrm{L}$ for luteinizing hormone (LH) and follicle-stimulating hormone (FSH), respectively (20). The coefficients of variation for LH and FSH are $<7 \%$ for the range of values under study. Estradiol (E2), estrone (E1), total testosterone (TT), and androstenedione (AD) were measured by liquid chromatography-mass spectrometry (Triple Quad $^{\text {TM }} 6500$ LC/MS/MS System, AB SCIEX, Framingham, MA) at the Division of Laboratory Sciences, National Center for Environmental Health, Centers for Disease Control and Prevention (Atlanta, GA). The assay limits of detection (LOD) are: E2 $1.72 \mathrm{pg} / \mathrm{mL}, \mathrm{E} 1$ $0.13 \mathrm{ng} / \mathrm{dL}$, TT $0.57 \mathrm{ng} / \mathrm{dL}$, and AD $0.82 \mathrm{ng} / \mathrm{dL}$. All hormone measurements were above the LOD except for $\mathrm{E} 2$ in $12 \mathrm{NW}$ and $10 \mathrm{OB}$ girls.

Urine was collected from 43 subjects ( $25 \mathrm{NW}, 18 \mathrm{OB}$ ) to obtain vaginal cells for calculation of a modified vaginal maturation index (mVMI). Urine (10-50 cc) was spun at $2000 \mathrm{rpm}$ for 10 minutes, and the cell pellet was transferred to a 20-ml vial of ThinPrep PreservCyt preservative (Hologic, Marlborough, MA). Vials were stored at room temperature for no more than two weeks before analysis. Samples were processed according to standard clinical procedures at the National Cancer Institute (NCI) Cytopathology Section, Laboratory of Pathology (Bethesda, MD). Cells were processed into a monolayer preparation, stained with Papanicolaou stain, and at least 100 cells were counted by a cytotechnologist and reviewed by a pathologist. In contrast to a sample obtained by swabbing the vaginal mucosa, when analyzing a urine sample, desquamated parabasal and intermediate cells of vaginal origin 
cannot be reliably distinguished from transitional cells of bladder origin. Cells were therefore classified as either superficial (mature, indicative of estrogen exposure) or nonsuperficial (other) and the percent of superficial squamous cells was calculated as a mVMI, as previously described (21). Repeat urine samples were obtained whenever inflammatory cells were present.

Breast Ultrasound-Breast morphological stage was determined by ultrasound using a linear transducer (Samsung H60, 6-4 Hz or Toshiba Nemio 30, $12 \mathrm{~Hz}$ ) and classified, as stage A (no breast bud), stage B (bud $<1 \mathrm{~cm}$ and circular), stage C (bud $>1 \mathrm{~cm}$ and circular), stage D (bud with several branches extending into surrounding stromal matrix), or stage E (extensive branching) [Figure 1], as previously described (22). Breast ultrasounds were performed by a single investigator (NDS) and images were reviewed by a sonographer (JMA) blinded to the subject's age and Tanner stage. Note that breast fat content cannot be reliably determined by breast ultrasound.

Pelvic Ultrasound-A trans-abdominal pelvic ultrasound was performed using the fullbladder technique and a curved, 6-4 Hz transducer (Siemens S-2000, Mountain View, CA). Maximum follicle diameter, ovarian and uterine dimensions, and endometrial thickness were recorded. Uterine and ovarian volumes were calculated using the formula for an ellipsoid (L x $\mathrm{H} \mathrm{x} \mathrm{W} \mathrm{x} \mathrm{0.523).} \mathrm{Both} \mathrm{ovaries} \mathrm{were} \mathrm{visualized} \mathrm{in} 67$ subjects, one ovary was visualized in 11 subjects, and neither ovary was visualized in 2 subjects. All images were independently reviewed by trained research staff and a random sample of 20 scans was also reviewed by a blinded investigator.

Dual-Energy X-ray Absorptiometry (DXA)—Subjects underwent a DXA (GE Medical Systems Lunar, Madison, WI, USA; software version 13.60.033) to determine total percent body fat, percent gynoid fat (i.e., percent of hip and upper thigh tissue made up of fat), and percent android fat (i.e., percent of tissue between the ribs and pelvis made up of fat). A negative pregnancy test was documented before the exam.

Bone Age (BA) - An x-ray of the left hand was taken and skeletal age was determined by a single investigator (NDS) blinded to the subject's age using the Greulich and Pyle atlas (23).

Data Analysis-Sample size calculations determined that 30 subjects per weight group were required to demonstrate a 30-40\% difference in the misclassification rate of breast tissue by Tanner staging (vs ultrasound) between groups with $80 \%$ power. For this calculation, breast development was assumed to be overestimated in NW at a rate of 10 $15 \%$, as shown previously (22).

Subject characteristics are presented according to age-adjusted BMI (body mass index) categories of normal weight [NW] $\left(5^{\text {th }}\right.$ to $<85^{\text {th }}$ percentile) or overweight/obese ( $\left.285^{\text {th }}\right)$ (24) to best illustrate the composition of the cohort in a clinical context. Age-adjusted percent body fat percentiles and Z-scores were assigned based on smoothed reference curves for US children from the CDC (25). Characteristics of NW and OB were compared by t-test or Fisher's exact test. The false positive rate for Tanner staging (i.e., girls with breast 
morphological stage A on ultrasound misclassified as Tanner stage II or greater on physical exam) was reported with Wilson score confidence intervals (26).

Multiple linear regression was used to determine the relationship between percent total body fat or percent gynoid fat and: 1) measures of systemic estrogen action (uterine volume, endometrial thickness, difference between BA and chronologic age, mVMI);2) measures of FSH action (maximum ovarian volume and follicle size) $(27,28) ; 3$ ) gonadotropin and sex steroid levels (LH, FSH, AD, TT, E1, E2); and 4) indices of aromatase action (E2/TT and E1/AD). All regression models were adjusted for breast morphological stage.

Homoscedasticity of residuals across breast morphological stages was confirmed using Levene's test. Uterine volume, endometrial thickness, and hormone measures were natural log-transformed before analysis due to non-Gaussian distributions. Regression models were also performed after adjusting uterine volume for age (29) and height (30); ovarian volume for age (31); and gonadotropins for the time of blood draw with no effect on the results. Tobit regression was used for analyses that included E2 because of left-censoring (i.e., E2 values below the LOD) (32). Analyses were repeated using percent gynoid fat because aromatase expression is highest in the buttocks and thighs (33). Tests for a linear trend in the outcome variable in association with increasing breast morphologic stage were conducted for each regression model. Pearson (or Spearman, where appropriate) correlation coefficients were determined between BA or BA advancement (defined as BA minus chronological age) and clinical and biochemical parameters. All analyses were performed using Stata 15.1 (College Station, TX).

\section{RESULTS}

\section{Subject Characteristics: Anthropometrics and Body Composition}

Eighty subjects (68\% NW, 32\% OB) were studied (Table 1). OB were younger than NW and were more likely to be non-Hispanic Black or Hispanic $(\mathrm{p}=0.03)$. Percent body fat, determined by total body DXA, ranged from $13.1-53.5 \%$ which corresponds to the $3^{\text {rd }}-97^{\text {th }}$ percentiles (or Z-scores of -2.1 to 2.5) on age-adjusted, smoothed reference curves for US girls (25). OB had a greater waist circumference, waist-to-hip ratio, total percent body fat (41.10 1; 0.94 vs. $26.80 \pm 0.88 \%$, p $<0.0001)$, percent gynoid fat ( $45.20 \pm 1.12$ vs. 35.00 $\pm 0.84 \%, \mathrm{p}<0.0001)$, and percent android fat $(44.60 \pm 1.30$ vs. $22.80 \pm 1.20 \%, \mathrm{p}<0.001)$ than NW. Bone age was advanced by one year, on average, in OB. Bone age was positively correlated with age, Tanner breast and pubic hair stages, breast morphological stage, maximum ovarian volume, maximum follicle size, uterine volume, endometrial thickness, mVMI, as well as AD, TT, and E2 levels (Supplementary Table 1), whereas BA advancement correlated with waist-hip ratio $(\mathrm{r}=0.27, \mathrm{p}=0.01)$ and $\mathrm{BMI} \mathrm{Z} \mathrm{Z}$-score $(\mathrm{r}=0.36$, $\mathrm{p}=0.001$ ).

The correlation between BMI and adiposity varies by age, weight, and race/ethnicity (3436 ), and indeed, we found that only $77.0 \%$ of girls classified as overweight/obese according to BMI had high adiposity (defined as a body fat percentile $\geq 80^{\text {th }}$ based on a higher risk of metabolic syndrome; modified from Weber et al. who used the fat mass index $80^{\text {th }}$ percentile as a cut point (37)), whereas $3.8 \%$ of girls classified as normal weight had high adiposity. 
Thus, total percent body fat was utilized in all analyses to best address the specific effect of body fat on pubertal development.

\section{Pubertal Development}

The distribution of Tanner breast and pubic hair stages was similar in NW and OB (Table 1). Although parents reported that their daughter had breast development at the time of enrollment, a small number of subjects ( $3 \mathrm{NW}$ and $4 \mathrm{OB}$ ) were found to have Tanner I breasts on physical exam.

\section{Relationship of Breast Morphology, Other Indices of Estrogen Activity, and Percent Body Fat}

Breast morphological stage was assigned according to an ultrasound-based grading system established by Bruni et al. (22) where stage A represents the pre-pubertal breast and stage $\mathrm{E}$ a fully mature breast. The full spectrum of breast development (A-E) was observed among subjects with stages D and E being the most common stages (59\%) overall (Figure 1, Table 1). Consistent with previous studies (22), there was not a 1:1 relationship between Tanner breast stage and breast morphological stage: Tanner III breasts corresponded to breast ultrasound stages B-E, Tanner IV to stages D-E, and Tanner V to stages C-E, indicating the relative imprecision of physical examination in the determination of breast maturity. Ultrasound confirmed the pre-pubertal status of six of seven girls classified as Tanner I; the remaining girl, who was NW, was found to have a small $(<1 \mathrm{~cm})$ breast bud on ultrasound (stage B). In four OB girls, adipose tissue in the chest area was mistaken for true breast tissue by inspection and palpation (Tanner II/III on exam, breast stage A on ultrasound), representing a false positive rate of $40 \%$ (95\% CI 16-69\%). Characteristics of these four OB are presented in Table 2. NW tended to have more advanced breast morphology than OB, but this difference was attenuated after accounting for the older age in NW ( $\mathrm{p}=0.1)$ (Table 1).

Overall, the cohort demonstrated the expected estrogen-induced changes in the uterus and endometrium with increasing maturity of breast morphological stage, with a linear increase in uterine length, uterine volume, and endometrial thickness ( $\mathrm{p}<0.001$ for all) (Figure 2). Uterine length and volume were also positively correlated with height $(\beta=0.05, \mathrm{p}=0.001$ and $\beta=0.03, p=0.004$, respectively) but were not related to subject age $(p=0.3$ and $p=0.8$, respectively). Maximum ovarian volume $(\mathrm{p}=0.02)$ and maximum follicle diameter $(\mathrm{p}<0.001)$ increased with advancing breast maturity, and ovarian volume also appeared related to age ( $\beta=0.45, p=0.06)$. The $m V M I$ tended to increase with advancing breast maturity $(p=0.08)$, and bone age advancement did not correlate with breast maturity $(\mathrm{p}=0.8)$. Neither percent body fat nor percent gynoid fat influenced uterine dimensions or endometrial thickness [Table 3] when adjusted for breast morphological stage. Body fat also had no effect on BA advancement in girls matched on breast morphological stage.

\section{Relationship of Breast Morphology, Reproductive Hormones, and Percent Body Fat}

Sex steroids (E1, E2, AD, TT) and gonadotropins (LH, FSH) increased linearly with advancing breast morphological stage (Table 4) and were not affected by total or gynoid body fat (Table 3). Maximum ovarian volume and follicle size, which reflect FSH action, were also independent of total and gynoid fat (Table 3). Total body fat and gynoid fat 
similarly had no effect on indices of aromatase activity (E1/AD and E2/TT) in analyses controlled for breast morphological stage (Table 3).

\section{DISCUSSION}

We performed detailed reproductive phenotyping in pubertal girls with either overweight/ obesity or normal weight to understand how excess body fat may contribute to earlier breast development in girls (Fig 3). While thelarche is typically the result of activation of the neuroendocrine components of the reproductive axis (LH and FSH) and estrogen production by the ovary, it has been proposed that adipose tissue, which expresses aromatase, may also be a relevant source of estrogen in OB. In the current studies, however, we found no differences in serum E1 and E2 levels or in indices of aromatase action (AD/E1, TT/E2) as a function of body fat in girls of the same pubertal stage. These findings are consistent with previous studies (8-10) in suggesting that peripheral adipose tissue may not explain earlier thelarche in OB. By using a novel, non-invasive approach, we showed further that local production of estrogen by breast adipose tissue is also unlikely to account for earlier breast development in OB.

Indeed, the breast is unique among estrogen-sensitive organs (e.g. uterus, bone) in that it has an adipose depot all its own - the mammary fat pad. The potential role of this particular fat pad in inducing breast development in OB has not been previously investigated. Studies in the rodent have shown that early in development, the mammary bud elongates and invades the mammary fat pad in response to a signaling cascade between these two structures (12, 38). Studies of human infant breast tissue have also identified developing ducts in close proximity to or encased by fat (11). This early rudimentary ductal structure remains in place until puberty, when ovarian steroids drive ductal elongation, branching, and the formation of lobuloalveolar units. As mammary fat expresses aromatase and synthesizes estrogen de novo (39), we hypothesized that in OB girls, increased mammary fat could provide a source of local estrogen and induce isolated breast growth independent from the hypothalamicpituitary-ovarian (HPO) axis.

Mammary fat estrogen content cannot be measured in healthy pediatric research subjects. We therefore examined the relationship between breast morphological stage and other indices of estrogen action (uterine dimensions, endometrial thickness, BA, and mVMI) in girls over a range of body fat. We assumed that a higher total percent body fat, as determined by DXA, was associated with a higher breast fat content in girls based on previous studies demonstrating a positive correlation between BMI and breast fat in women and girls undergoing breast reduction mammoplasty (40-42). Studies in healthy women and girls have reported a similar relationship using non-invasive imaging techniques. Novotny et al., for example, used whole-body DXA and breast-specific DXA and a 2-compartment model of the breast (a fat compartment and fibroglandular compartment) to demonstrate that percent body fat was inversely correlated with breast fibroglandular density in girls (and therefore, positively correlated with breast fat) (13). MRI studies of the breast in girls and young women $(43)$ and in adults $(14,15)$ have shown a positive association between body weight and total breast fat. In further support of a relationship between total body fat and breast fat, percent truncal fat (as determined by DXA) is correlated with breast adipocyte 
size (44) and there is a proportionate decrease in breast, visceral, and subcutaneous fat mass after diet-induced weight loss (14). If estrogen derived from mammary fat influences breast development in girls, we expected to find that, in girls with the same breast morphological stage, those with more body fat would demonstrate immaturity of other estrogen-sensitive tissues compared with girls with less body fat. Instead, we observed that girls who differed in total body fat had comparable end-organ markers of systemic estrogen exposure. Thus, these findings do not support the hypothesis that excessive mammary fat in OB girls contributes to breast development.

Aberrant central regulation of the HPO axis may also be responsible for the observation of earlier thelarche without significantly earlier menarche in OB. That is, the reproductive axis is activated earlier but takes longer to reach mature function (45). In support of this hypothesis, secondary analysis of LH levels in a small group of pre-pubertal girls (46) demonstrated that the OB were more likely to demonstrate increased LH secretion during sleep than their NW peers (45), suggesting earlier central activation in OB. A study using NHANES III data also found that pre-adolescent weight gain predicts earlier central activation, but only in OB born small for gestational age (47). In contrast, studies in early/ mid-pubertal girls have consistently demonstrated a blunted nocturnal rise in LH in OB compared with NW of the same Tanner breast stage $(46,48)$, suggesting an attenuation of neuroendocrine activity in $\mathrm{OB}$ by mid-puberty. An alternative explanation for lower nocturnal LH levels in OB, however, is that pre-pubertal OB may have been misclassified as early pubertal using Tanner staging, as discussed below. We found no association between percent body fat and daytime LH or FSH levels or two indices of FSH action (ovarian volume and follicle size) in girls in whom pubertal stage was precisely determined by ultrasound-based breast morphological staging. With data from a single point in time, however, we cannot comment on the potential influence of body fat on the pace of puberty as girls with more body fat may have spent a longer time at a given breast morphological stage than those with less body fat.

The current studies suggest that misclassification of adipose tissue as breast tissue may in part explain reports of earlier breast development among OB. The difficultly in distinguishing glandular from adipose chest tissue on physical exam was recognized well before the current obesity epidemic and led to a recommendation to use additional physical exam findings such as the palpable depression beneath the nipple that is present in chest adipose but not glandular tissue (18) and the Garn and Falkner areolar staging system (19, 49), which takes into account areolar diameter, pigmentation, and shape. In the current studies, none of the OB girls who were misjudged to be pubertal (categorized as Tanner breast stage II/III but had breast morphological stage A) had areolar stippling, which is typically associated with Tanner III breasts (50). However, as noted by others, areolar diameter shows too much inter-individual variability to be a useful criterion for thelarche in cross-sectional studies $(51,52)$ and is related not only to estrogen action but also to truncal subcutaneous fat thickness (53). The absence of areolar pigmentation scales appropriate for minorities also limits the utility of this measure. While a recent study comparing breast MRI (gold standard) and Tanner staging found that Tanner staging could reliably detect glandular breast tissue in girls, this study was limited by the inclusion of only nine OB out of 100 participants studied (54). Consistent with our findings, another study focused on obese, 
Tanner II/III girls found that Tanner staging overestimated breast maturation as determined by ultrasound in $35 \%$ of cases (55). Thus, misclassification bias in pubertal staging of OB is a potential confounder in studies of pubertal timing.

Obesity affects not only pubertal development, but also linear growth and growth plate maturation. Consistent with previous studies, we found that BA advancement was positively correlated with BMI Z-score $(9,56-59)$ and not with E2 $(57,59)$. We also found no relationship to E1, TT, and AD levels, but did not measure other proposed mediators of BA advancement such as dehydroepiandrosterone sulfate (DHEAS), insulin-like growth factor 1 (IGF-1), insulin, leptin, or the rate of weight gain in participants $(57,59)$.

This study had several limitations. We could not measure breast adipose tissue or breast estrogen content directly in these healthy pediatric subjects. As such, we cannot completely rule-out the possibility of paracrine estrogen action in the adolescent breast. While breast ultrasound affords a more quantitative and objective assessment of breast maturation than Tanner staging, there have been no studies to specifically investigate the reproducibility of this technique, and in the current studies, both Tanner staging and breast ultrasounds were performed by a single, unblinded investigator.

In conclusion, comprehensive reproductive phenotyping of pubertal girls across a range of body weight and fat indicates a positive relationship between breast morphological stage and other markers of peripheral estrogen action but does not support the hypothesis that estrogen derived from mammary fat contributes to breast development in OB. We also find no evidence that estrogen derived from total body fat influences breast development as serum estrogen levels and indices of aromatase action were independent of percent body fat. It remains possible that obese girls may be more vulnerable to an environmental agent that preferentially activates estrogen receptors in breast tissue. Longitudinal follow-up of this cohort is now underway to investigate the potential effect of body fat on the maturational trajectory of the neuroendocrine components of the female reproductive axis.

\section{Supplementary Material}

Refer to Web version on PubMed Central for supplementary material.

\section{Acknowledgements}

We thank and acknowledge the staff of the Clinical Research Unit, Wake Radiology, and Social and Scientific Systems, Inc. for their support in conducting these studies. We thank Dr. Deborah C. terMeulen (Breast Imaging Division, Massachusetts General Hospital) for assistance with breast ultrasound imaging and interpretation and Paul Kim (Battelle) for technical assistance. We thank Dr. Janet E. Hall for her helpful discussions and careful review of the manuscript.

Funding support: This work was supported, in part, by the Intramural Research Program of the NIH, National Institute of Environmental Health Sciences (Z01-ES103315) and by Grant Number 1UL1TR001102. NDS is also supported as a Lasker Clinical Research Scholar (1SI2ES025429-01). The content is solely the responsibility of the authors and does not necessarily represent the official views of the National Center for Research Resources, the National Center for Advancing Translational Science or the National Institutes of Health. The findings and conclusions in this paper have not been formally disseminated by the Centers for Disease Control and Prevention, the Agency for Toxic Substances and Disease Registry, and should not be construed to represent any agency determination or policy. Use of trade names and commercial sources is for identification only and does not constitute endorsement by the U.S. Department of Health and Human Services or the U.S. Centers for Disease Control and Prevention. 


\section{REFERENCES}

1. Li W, Liu Q, Deng X, Chen Y, Liu S, Story M. Association between Obesity and Puberty Timing: A Systematic Review and Meta-Analysis. Int J Environ Res Public Health 2017;14(10).

2. Sorensen K, Mouritsen A, Aksglaede L, Hagen CP, Mogensen SS, Juul A. Recent secular trends in pubertal timing: implications for evaluation and diagnosis of precocious puberty. Horm Res Paediatr. 2012;77(3):137-45. [PubMed: 22508036]

3. Cunningham SA, Kramer MR, Narayan KM. Incidence of childhood obesity in the United States. N Engl J Med. 2014;370(5):403-11. [PubMed: 24476431]

4. Biro FM, Galvez MP, Greenspan LC, Succop PA, Vangeepuram N, Pinney SM, et al. Pubertal assessment method and baseline characteristics in a mixed longitudinal study of girls. Pediatrics. 2010;126(3):e583-90. [PubMed: 20696727]

5. Lee JM, Appugliese D, Kaciroti N, Corwyn RF, Bradley RH, Lumeng JC. Weight status in young girls and the onset of puberty. Pediatrics. 2007;119(3):e624-30. [PubMed: 17332182]

6. Davison KK, Susman EJ, Birch LL. Percent body fat at age 5 predicts earlier pubertal development among girls at age 9. Pediatrics. 2003;111(4 Pt 1):815-21. [PubMed: 12671118]

7. Rubin C, Maisonet M, Kieszak S, Monteilh C, Holmes A, Flanders D, et al. Timing of maturation and predictors of menarche in girls enrolled in a contemporary British cohort. Paediatric and perinatal epidemiology. 2009;23(5):492-504. [PubMed: 19689500]

8. de Ridder CM, Bruning PF, Zonderland ML, Thijssen JH, Bonfrer JM, Blankenstein MA, et al. Body fat mass, body fat distribution, and plasma hormones in early puberty in females. J Clin Endocrinol Metab. 1990;70(4):888-93. [PubMed: 2318946]

9. Klein KO, Larmore KA, de Lancey E, Brown JM, Considine RV, Hassink SG. Effect of obesity on estradiol level, and its relationship to leptin, bone maturation, and bone mineral density in children. J Clin Endocrinol Metab. 1998;83(10):3469-75. [PubMed: 9768648]

10. Birkebaek NH, Lange A, Holland-Fischer P, Kristensen K, Rittig S, Vilstrup H, et al. Effect of weight reduction on insulin sensitivity, sex hormone-binding globulin, sex hormones and gonadotrophins in obese children. Eur J Endocrinol. 2010;163(6):895-900. [PubMed: 20829367]

11. Anbazhagan R, Bartek J, Monaghan P, Gusterson BA. Growth and development of the human infant breast. The American journal of anatomy. 1991;192(4):407-17. [PubMed: 1781450]

12. Neville MC, Medina D, Monks J, Hovey RC. The Mammary Fat Pad. Journal of Mammary Gland Biology and Neoplasia. 1998;3(2):109-16. [PubMed: 10819521]

13. Novotny R, Daida Y, Morimoto Y, Shepherd J, Maskarinec G. Puberty, body fat, and breast density in girls of several ethnic groups. Am J Hum Biol. 2011;23(3):359-65. [PubMed: 21445936]

14. Schautz B, Later W, Heller M, Muller MJ, Bosy-Westphal A. Associations between breast adipose tissue, body fat distribution and cardiometabolic risk in women: cross-sectional data and weightloss intervention. European journal of clinical nutrition. 2011;65(7):784-90. [PubMed: 21427743]

15. Zhu W, Huang P, Macura KJ, Artemov D. Association between breast cancer, breast density, and body adiposity evaluated by MRI. European radiology. 2016;26(7):2308-16. [PubMed: 26489749]

16. Fryar CD, Gu Q, Ogden CL. Anthropometric reference data for children and adults: United States, 2007-2010. Vital and health statistics Series 11, Data from the national health survey. 2012(252): $1-48$.

17. Marshall WA, Tanner JM. Variations in pattern of pubertal changes in girls. ArchDisChild. 1969;44(235):291-303.

18. Blum A The Doughnut Sign. Pediatrics. 1990;86(6):1001-.

19. Biro FM, Falkner F, Khoury P, Morrison JA, Lucky AW. Areolar and breast staging in adolescent girls. Adolescent and Pediatric Gynecology. 1992;5(4):271-2.

20. Chan YM, Lippincott MF, Butler JP, Sidhoum VF, Li CX, Plummer L, et al. Exogenous kisspeptin administration as a probe of GnRH neuronal function in patients with idiopathic hypogonadotropic hypogonadism. J Clin Endocrinol Metab. 2014;99(12):E2762-71. [PubMed: 25226293]

21. Adgent MA, Flake GP, Umbach DM, Stallings VA, Bernbaum JC, Rogan WJ. Urogenital epithelial cells as simple markers of estrogen response in infants: methods and applications. PloS one. 2013;8(10):e77061. [PubMed: 24146956] 
22. Bruni VD M; Deligeoroglou E; Innocenti P; Pandimiglio AM; Magini A; Bassi F Breast development in adolescent girls. Adolescent and Pediatric Gynecology. 1990;3:201-5.

23. Greulich WW, Pyle SI. Radiographic atlas of skeletal development of the hand and wrist. $2 \mathrm{~d}$ ed. Stanford, Calif.,: Stanford Univ. Press; 1959 xvi, 256 p. p.

24. Barlow SE. Expert committee recommendations regarding the prevention, assessment, and treatment of child and adolescent overweight and obesity: summary report. Pediatrics. 2007;120 Suppl 4:S164-S92. [PubMed: 18055651]

25. Ogden CL, Li Y, Freedman DS, Borrud LG, Flegal KM. Smoothed percentage body fat percentiles for U.S. children and adolescents, 1999-2004. National health statistics reports. 2011(43):1-7.

26. Agresti A, Coull BA. Approximate is Better than "Exact" for Interval Estimation of Binomial Proportions. The American Statistician. 1998;52(2):119-26.

27. Stanhope R, Adams J, Jacobs HS, Brook CG. Ovarian ultrasound assessment in normal children, idiopathic precocious puberty, and during low dose pulsatile gonadotrophin releasing hormone treatment of hypogonadotrophic hypogonadism. Archives of disease in childhood. 1985;60(2): 116-9. [PubMed: 3883909]

28. Cacciatore B, Apter D, Alfthan H, Stenman U-H. Ultrasonic characteristics of the uterus and ovaries in relation to pubertal development and serum LH, FSH, and estradiol concentrations. Adolescent and Pediatric Gynecology. 1991;4(1):15-20.

29. Kelsey TW, Ginbey E, Chowdhury MM, Bath LE, Anderson RA, Wallace WH. A Validated Normative Model for Human Uterine Volume from Birth to Age 40 Years. PloS one. 2016;11(6):e0157375. [PubMed: 27295032]

30. Hagen CP, Mieritz MG, Nielsen JE, Anand-Ivell R, Ivell R, Juul A. Longitudinal assessment of circulating insulin-like peptide 3 levels in healthy peripubertal girls. Fertility and sterility. 2015;103(3):780-6.e1. [PubMed: 25516081]

31. Kelsey TW, Dodwell SK, Wilkinson AG, Greve T, Andersen CY, Anderson RA, et al. Ovarian volume throughout life: a validated normative model. PloS one. 2013;8(9):e71465. [PubMed: 24019863]

32. Lubin JH, Colt JS, Camann D, Davis S, Cerhan JR, Severson RK, et al. Epidemiologic evaluation of measurement data in the presence of detection limits. Environmental health perspectives. 2004;112(17):1691-6. [PubMed: 15579415]

33. Bulun SE, Simpson ER. Competitive reverse transcription-polymerase chain reaction analysis indicates that levels of aromatase cytochrome P450 transcripts in adipose tissue of buttocks, thighs, and abdomen of women increase with advancing age. JClinEndocrinolMetab. 1994;78(2): 428-32.

34. Flegal KM, Ogden CL, Yanovski JA, Freedman DS, Shepherd JA, Graubard BI, et al. High adiposity and high body mass index-for-age in US children and adolescents overall and by raceethnic group. The American Journal of Clinical Nutrition. 2010;91(4):1020-6. [PubMed: 20164313]

35. Freedman DS, Wang J, Thornton JC, Mei Z, Pierson RN Jr., Dietz WH, et al. Racial/ethnic differences in body fatness among children and adolescents. Obesity (Silver Spring, Md). 2008;16(5):1105-11.

36. Dugas LR, Cao G, Luke AH, Durazo-Arvizu RA. Adiposity Is Not Equal in a Multi-Race/Ethnic Adolescent Population: NHANES 1999-2004. Obesity. 2011;19(10):2099-101. [PubMed: 21436795]

37. Weber DR, Leonard MB, Shults J, Zemel BS. A comparison of fat and lean body mass index to BMI for the identification of metabolic syndrome in children and adolescents. J Clin Endocrinol Metab. 2014;99(9):3208-16. [PubMed: 24926951]

38. Zwick RK, Guerrero-Juarez CF, Horsley V, Plikus MV. Anatomical, Physiological, and Functional Diversity of Adipose Tissue. Cell metabolism. 2018;27(1):68-83. [PubMed: 29320711]

39. Falk RT, Gentzschein E, Stanczyk FZ, Brinton LA, Garcia-Closas M, Ioffe OB, et al. Measurement of sex steroid hormones in breast adipocytes: methods and implications. Cancer epidemiology, biomarkers \& prevention : a publication of the American Association for Cancer Research, cosponsored by the American Society of Preventive Oncology. 2008;17(8):1891-5. 
40. Cruz-Korchin N, Korchin L, Gonzalez-Keelan C, Climent C, Morales I. Macromastia: how much of it is fat? Plastic and reconstructive surgery. 2002;109(1):64-8. [PubMed: 11786793]

41. Lejour M Evaluation of fat in breast tissue removed by vertical mammaplasty. Plastic and reconstructive surgery. 1997;99(2):386-93. [PubMed: 9030144]

42. Said TA, Khodair FF, Ahmad TM. A study of breast fat content in Egyptians and the applicability of liposuction as an adjunctive procedure in breast reductive surgery. Egypt J Plast Reconstr Surg. 2003;27(2):263-70.

43. Boyd N, Martin L, Chavez S, Gunasekara A, Salleh A, Melnichouk O, et al. Breast-tissue composition and other risk factors for breast cancer in young women: a cross-sectional study. The Lancet Oncology. 2009;10(6):569-80. [PubMed: 19409844]

44. Vaysse C, Lomo J, Garred O, Fjeldheim F, Lofteroed T, Schlichting E, et al. Inflammation of mammary adipose tissue occurs in overweight and obese patients exhibiting early-stage breast cancer. NPJ Breast Cancer. 2017;3:19. [PubMed: 28649659]

45. Rosenfield RL, Bordini B. Evidence that obesity and androgens have independent and opposing effects on gonadotropin production from puberty to maturity. Brain research. 2010;1364:186-97. [PubMed: 20816944]

46. Bordini B, Littlejohn E, Rosenfield RL. Blunted sleep-related luteinizing hormone rise in healthy premenarcheal pubertal girls with elevated body mass index. JClinEndocrinolMetab. 2009;94(4): 1168-75.

47. Addo OY, Miller BS, Lee PA, Hediger ML, Himes JH. Age at hormonal onset of puberty based on luteinizing hormone, inhibin B, and body composition in preadolescent U.S. girls. Pediatric research. 2014;76(6):564-70. [PubMed: 25192395]

48. McCartney CR, Prendergast KA, Blank SK, Helm KD, Chhabra S, Marshall JC. Maturation of luteinizing hormone (gonadotropin-releasing hormone) secretion across puberty: evidence for altered regulation in obese peripubertal girls. JClinEndocrinolMetab. 2009;94(1):56-66.

49. Kimm SY, Barton BA, Obarzanek E, McMahon RP, Kronsberg SS, Waclawiw MA, et al. Obesity development during adolescence in a biracial cohort: the NHLBI Growth and Health Study. Pediatrics. 2002;110(5):e54. [PubMed: 12415060]

50. Fallat ME, Ignacio RC Jr. Breast disorders in children and adolescents. Journal of pediatric and adolescent gynecology. 2008;21(6):311-6. [PubMed: 19064223]

51. Buyukgebiz A, Kinik E. Nipple development in female puberty. The Turkish journal of pediatrics. 1989;31(4):275-9. [PubMed: 2486427]

52. Garn SM. Changes in areolar size during the steroid growth phase. Child development. 1952;23(1): 55-60. [PubMed: 14905500]

53. Roche AF, French NY, Davila GH. Areolar size during pubescence. Human biology. 1971;43(2): 210-23. [PubMed: 5117166]

54. Fugl L, Hagen CP, Mieritz MG, Tinggaard J, Fallentin E, Main KM, et al. Glandular breast tissue volume by magnetic resonance imaging in 100 healthy peripubertal girls: evaluation of clinical Tanner staging. Pediatr Res. 2016;80(4):526-30. [PubMed: 27384405]

55. Yuce O, Sevinc D. Ultrasonographic assessment of pubertal breast development in obese children: compliance with the clinic. Journal of pediatric endocrinology \& metabolism : JPEM. 2018;31(2): 137-41. [PubMed: 29374763]

56. Crocker MK, Stern EA, Sedaka NM, Shomaker LB, Brady SM, Ali AH, et al. Sexual dimorphisms in the associations of BMI and body fat with indices of pubertal development in girls and boys. $\mathrm{J}$ Clin Endocrinol Metab. 2014;99(8):E1519-29. [PubMed: 24780051]

57. de Groot CJ, van den Berg A, Ballieux B, Kroon HM, Rings E, Wit JM, et al. Determinants of Advanced Bone Age in Childhood Obesity. Horm Res Paediatr. 2017;87(4):254-63. [PubMed: 28365712]

58. De Simone M, Farello G, Palumbo M, Gentile T, Ciuffreda M, Olioso P, et al. Growth charts, growth velocity and bone development in childhood obesity. Int J Obes Relat Metab Disord. 1995;19(12):851-7. [PubMed: 8963351]

59. Klein KO, Newfield RS, Hassink SG. Bone maturation along the spectrum from normal weight to obesity: a complex interplay of sex, growth factors and weight gain. Journal of pediatric endocrinology \& metabolism : JPEM. 2016;29(3):311-8. [PubMed: 26565541] 


\section{Breast Morphological Staging by Ultrasound}
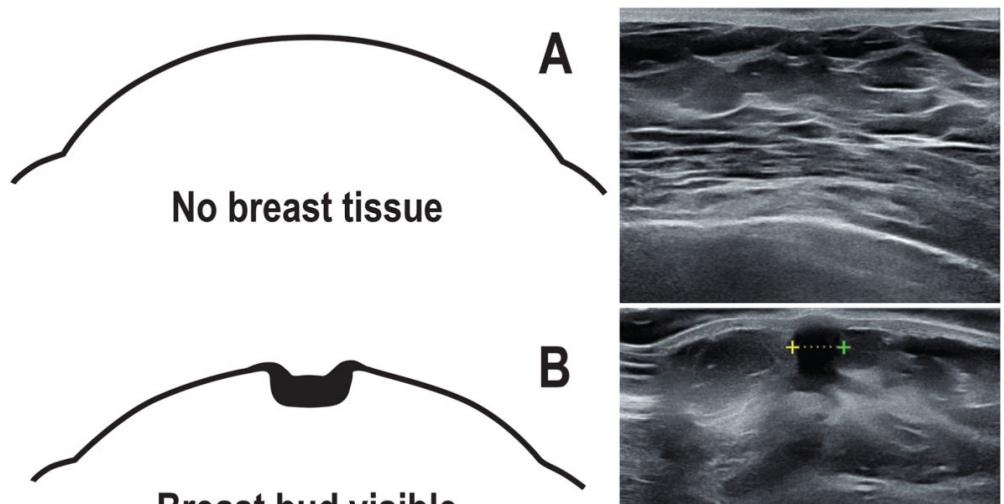

Breast bud visible

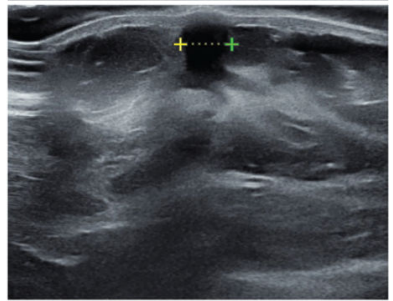

Areolar mounding with branching of glandular tissue

\section{Growth of breast bud}
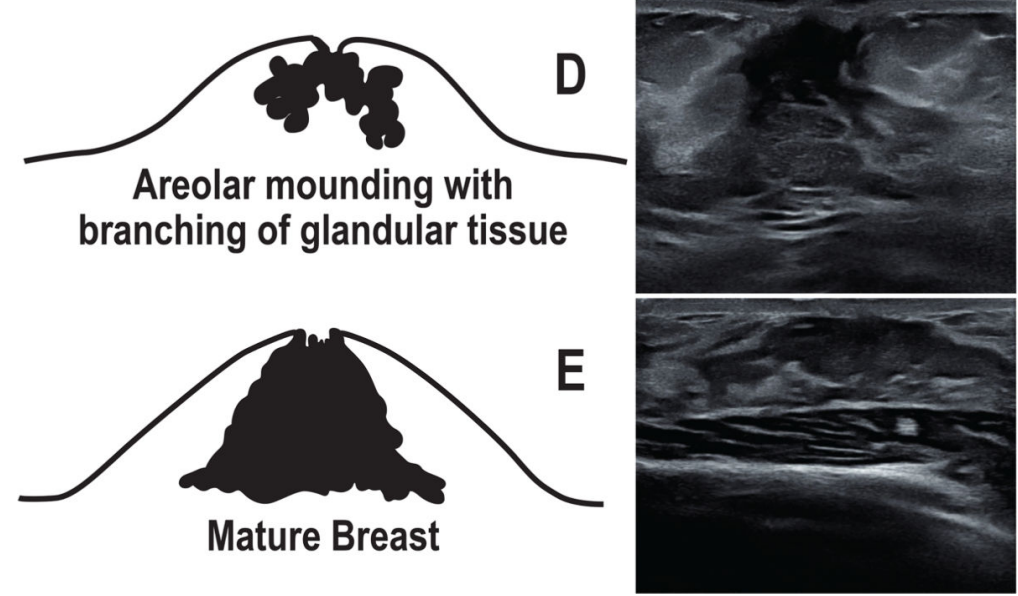

Figure 1.

Bruni scale of breast morphological stages during female pubertal development with corresponding breast ultrasound images from representative subjects in the current study. The breast bud diameter is marked by calipers (+---+) in ultrasound images of stages B and C. Adapted and reprinted with permission from "Breast Development in Adolescent Girls" by Bruni et al., Adolescent and Pediatric Gynecology, 3, Fig 1, p.203, Copyright Elsevier 1990 and from "Breast Disorders" by Mann et al. (eds.), Imaging of Gynecological Disorders in Infants and Children, Fig 5, p.229, Copyright Springer 2012. 

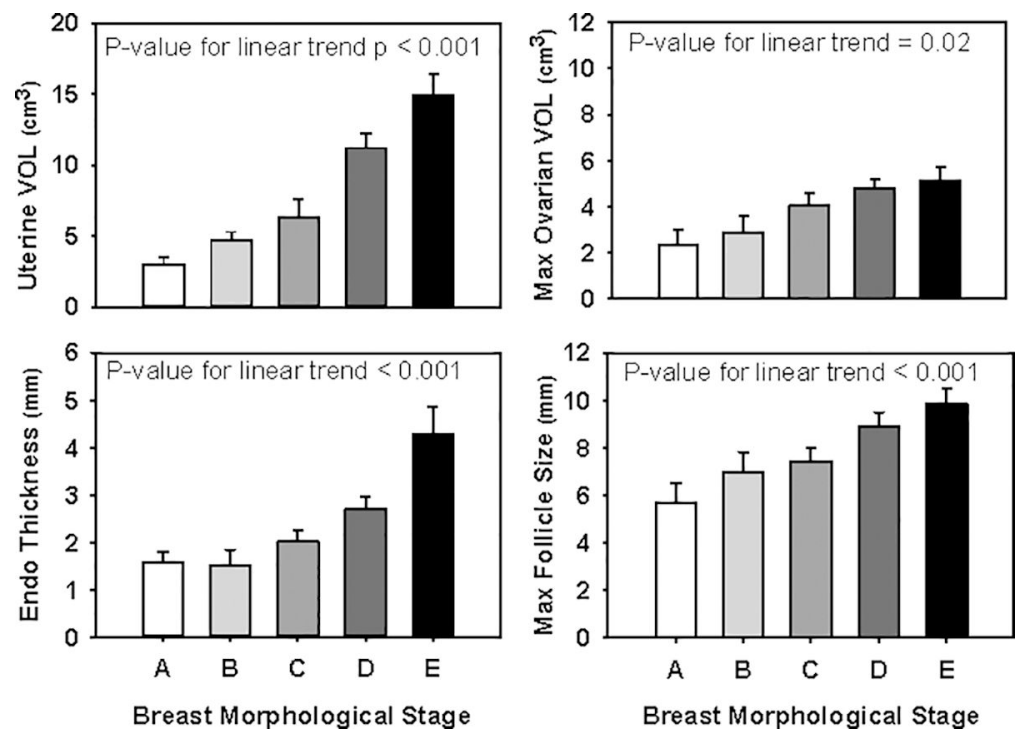

Figure 2.

Uterine volume, endometrial thickness, maximum ovarian volume, and maximum follicle size increased linearly with breast morphological stage maturity. Data is presented as means with standard error bars. 


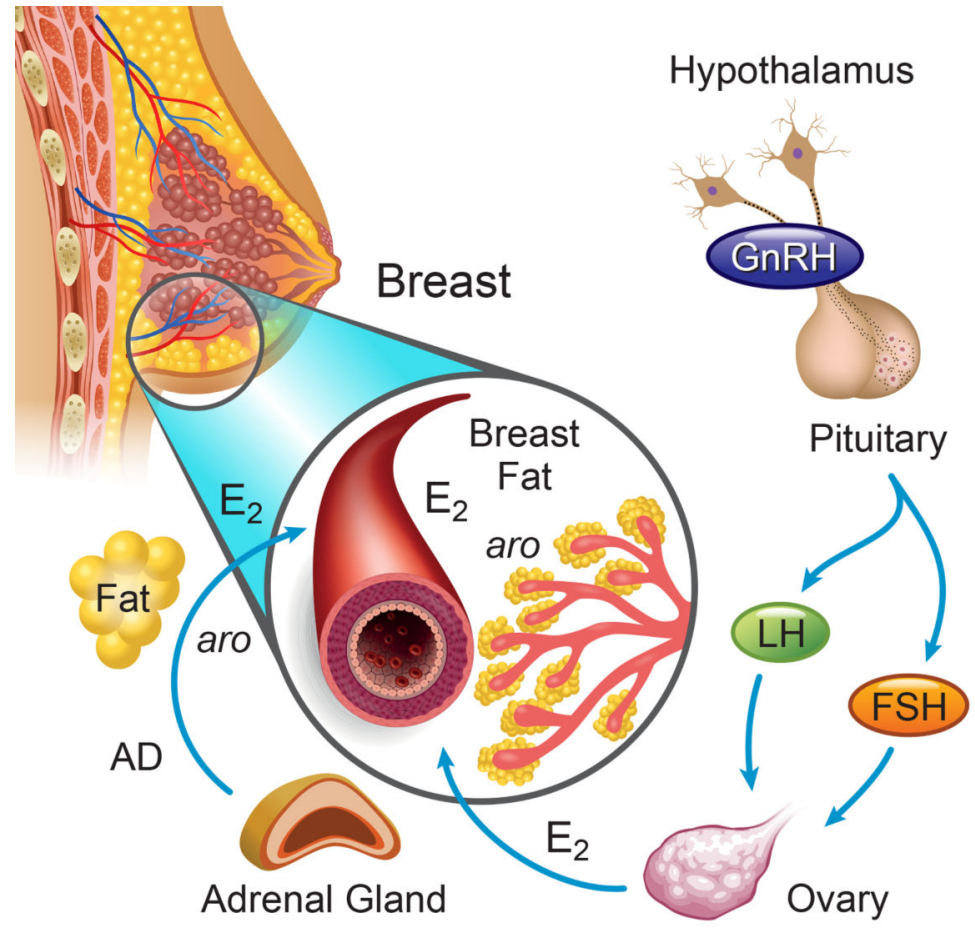

Figure 3.

Potential sources of increased estradiol (E2) responsible for earlier breast development in obese/overweight girls compared with normal weight girls. The ovary, once activated by the hypothalamic-pituitary unit, is the primary source of E2 during normal pubertal development. Adipose tissue expresses aromatase (aro) and adipocytes (yellow spheres) in peripubertal girls that reside either in the periphery or near the developing mammary epithelium may also influence systemic or local E2 exposure, respectively. Evidence to date, however, does not support a contribution of estrogen derived from adipose tissue in breast development in overweight/obese and normal weight girls. AD, androstenedione. 
Table 1.

Baseline characteristics of the cohort.

\begin{tabular}{|c|c|c|c|}
\hline & Normal Weight (NW) & Overweight/Obese (OB) & P-value \\
\hline $\mathrm{n}$ & 54 & 26 & \\
\hline Age (yrs; mean, SD) & $11.3(1.3)$ & $10.1(1.1)$ & $<0.001$ \\
\hline Race $(\mathrm{n}, \%)$ & & & 0.05 \\
\hline White, Non-Hispanic & $36(66.7)$ & $11(42.3)$ & \\
\hline Black, Non-Hispanic & $12(22.2)$ & $11(42.3)$ & \\
\hline Hispanic & $3(5.6)$ & $4(15.4)$ & \\
\hline Other & $3(5.6)$ & $0(0)$ & \\
\hline \multicolumn{4}{|l|}{ Anthropometrics (mean, SD) } \\
\hline BMI $\left(\mathrm{kg} / \mathrm{m}^{2}\right)$ & $17.6(1.7)$ & $23.8(3.1)$ & $\#$ \\
\hline BMI Z-score & $-0.12(0.7)$ & $1.70(0.4)$ & $\#$ \\
\hline Waist Circumference (cm) & $65.3(5.1)$ & $81.8(7.4)$ & $<0.001$ \\
\hline Waist-to-Hip Ratio & $0.8(0.05)$ & $0.9(0.04)$ & $<0.001$ \\
\hline Bone age (yrs; mean, SD) & $11.7(1.0)$ & $11.1(1.3)$ & 0.02 \\
\hline Bone age - Chronologic age (yrs; mean, SD) & $0.39(1.0)$ & $1.0(1.1)$ & 0.01 \\
\hline Breast Tanner Stage (n, \%) & & & 0.12 \\
\hline I & $3(5.6)$ & $4(15.4)$ & \\
\hline II & $0(0)$ & $2(7.7)$ & \\
\hline III & $38(70.4)$ & $13(50.0)$ & \\
\hline IV & $7(13.0)$ & $4(15.4)$ & \\
\hline $\mathrm{V}$ & $6(11.1)$ & $3(11.5)$ & \\
\hline Pubic Hair Tanner Stage (n, \%) & & & 0.35 \\
\hline I & $7(13.0)$ & $8(30.8)$ & \\
\hline II & $8(14.8)$ & $2(7.7)$ & \\
\hline III & $20(37.0)$ & $7(26.9)$ & \\
\hline IV & $15(27.8)$ & $6(23.1)$ & \\
\hline $\mathrm{V}$ & $4(7.4)$ & $3(11.5)$ & \\
\hline Breast morphological stage $(\mathrm{n}, \%)$ & & & 0.001 \\
\hline A & $2(3.7)$ & $8(30.8)$ & \\
\hline B & $3(5.6)$ & $6(23.1)$ & \\
\hline $\mathrm{C}$ & $11(20.4)$ & $3(11.5)$ & \\
\hline $\mathrm{D}$ & $21(38.9)$ & $4(15.4)$ & \\
\hline $\mathrm{E}$ & $17(31.5)$ & $5(19.2)$ & \\
\hline
\end{tabular}




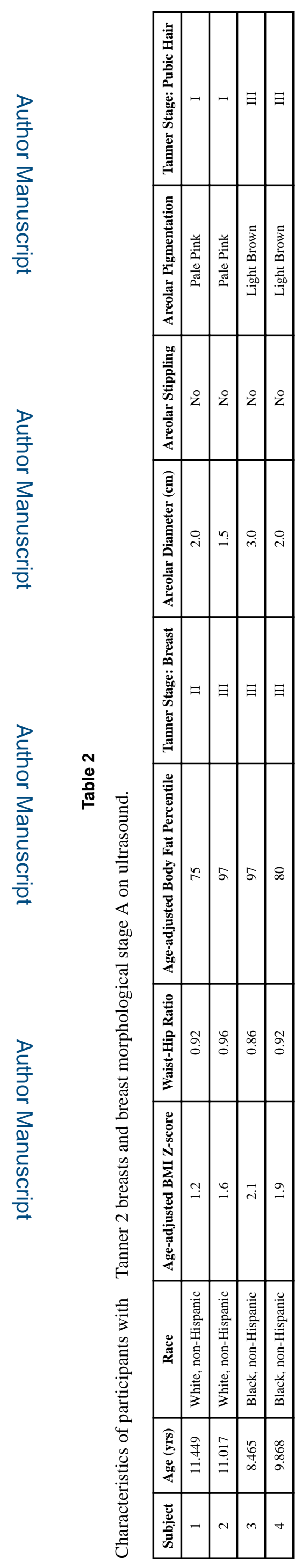


Table 3.

Results of multiple linear regression models testing the relationship between hormones or indices of estrogen action and either total percent body fat or percent gynoid fat controlled for breast morphological stage.

\begin{tabular}{|c|c|c|c|c|}
\hline \multirow[b]{2}{*}{ Indices of Estrogen Action } & \multicolumn{2}{|c|}{ Total Percent Body Fat } & \multicolumn{2}{|c|}{ Percent Gynoid Fat } \\
\hline & B coefficient $(95 \% \mathrm{CI})^{b}$ & P-Value & B coefficient $(95 \% \mathrm{CI})^{b}$ & P-Value \\
\hline Uterine volume $\left(\mathrm{cm}^{3}\right)$ & $0.005(-0.01,0.02)$ & 0.60 & $0.005(-0.016,0.025)$ & 0.65 \\
\hline Endometrial thickness (mm) & $-0.0005(-0.18,0.02)$ & 0.95 & $0.0009(-0.02,0.021)$ & 0.93 \\
\hline Bone age - Chronological age (yrs) & $0.02(-0.01,0.05)$ & 0.20 & $0.024(-0.015,0.06)$ & 0.22 \\
\hline Maximum ovarian volume $\left(\mathrm{cm}^{3}\right)$ & $0.03(-0.04,0.10)$ & 0.34 & $0.037(-0.04,0.12)$ & 0.37 \\
\hline Maximum follicle size (mm) & $0.002(-0.08,0.08)$ & 0.97 & $-0.006(-0.11,0.092)$ & 0.90 \\
\hline Modified VMI (\% superficial cells) & $-0.13(-0.69,0.43)$ & 0.64 & $-0.36(-0.95,0.23)$ & 0.22 \\
\hline \multicolumn{5}{|l|}{ Hormones $^{a}$} \\
\hline E1 & $0.008(-0.013,0.03)$ & 0.44 & $0.007(-0.018, .032)$ & 0.57 \\
\hline E2 & $0.01(-0.03,0.05)$ & 0.52 & $0.017(-0.031,0.065)$ & 0.48 \\
\hline $\mathrm{AD}$ & $0.003(-0.01,0.02)$ & 0.72 & $0.008(-0.009, .024)$ & 0.37 \\
\hline TT & $0.01(-0.005,0.02)$ & 0.21 & $0.02(-0.002,0.03)$ & 0.07 \\
\hline LH & $0.01(-0.03,0.05)$ & 0.59 & $0.019(-0.03,0.06)$ & 0.39 \\
\hline FSH & $-0.002(-0.02,0.01)$ & 0.82 & $-0.004(-0.02,0.01)$ & 0.63 \\
\hline $\mathrm{E} 1 / \mathrm{AD}$ & $0.004(-0.007,0.02)$ & 0.46 & $0.003(-0.01,0.02)$ & 0.70 \\
\hline $\mathrm{E} 2 / \mathrm{TT}$ & $0.004(-0.02,0.03)$ & 0.76 & $0.004(-0.03,0.04)$ & 0.80 \\
\hline
\end{tabular}

Percent gynoid fat (i.e., percent of hip and upper thigh tissue made up of fat) was tested separately because aromatase expression is highest in the buttocks and thighs.

${ }^{a}$ All hormones were natural $\log (\ln )$-transformed before analysis.

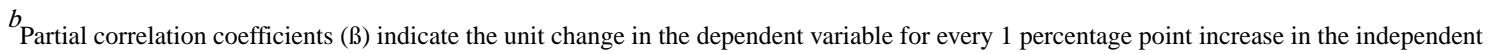
variable (percent body fat or gynoid fat). For natural $\log (\ln )$-transformed variables, $B \times 100$ represents the percent change in the independent variable for every 1 percentage point increase in percent body fat. VMI, vaginal maturation index; E1, estrone; E2, estradiol; AD, androstenedione; TT, total testosterone. To convert E2 to SI units (pmol/L), multiply by 3.67; for E1 (pmol/L), multiply by 3.69; for AD (nmol/L), multiply by 0.0349 ; for TT (nmol/L), multiply by 0.0347 . 
Table 4.

Gonadotropin and sex steroid levels according to breast morphological stage as determined by ultrasound.

\begin{tabular}{|c|c|c|c|c|c|c|}
\hline $\begin{array}{c}\text { Breast } \\
\text { Morphological } \\
\text { Stage }\end{array}$ & LH (IU/L) & FSH (IU/L) & E2 (pg/mL) & E1 (ng/dL) & TT (ng/dL) & $\mathrm{AD}(\mathrm{ng} / \mathrm{dL})$ \\
\hline A & $\begin{array}{c}0.05(0.04- \\
0.07)\end{array}$ & $\begin{array}{c}1.14(0.98- \\
1.77)\end{array}$ & $\begin{array}{l}1.22(1.22- \\
3.08)\end{array}$ & $\begin{array}{c}0.46(0.39- \\
0.59)\end{array}$ & $6.59(3.09-8.53)$ & $\begin{array}{c}22.39(13.47- \\
30.31)\end{array}$ \\
\hline B & $\begin{array}{c}0.10(0.06- \\
1.42)\end{array}$ & $\begin{array}{c}1.64(0.94- \\
2.77)\end{array}$ & $\begin{array}{l}2.21(1.22- \\
5.01)\end{array}$ & $\begin{array}{l}0.78(0.52- \\
\quad 3.01)\end{array}$ & $\begin{array}{c}8.76(5.53- \\
11.21)\end{array}$ & $\begin{array}{c}23.67(18.12- \\
34.04)\end{array}$ \\
\hline $\mathrm{C}$ & $\begin{array}{c}0.27(0.08- \\
1.52)\end{array}$ & $\begin{array}{c}2.54(1.87- \\
4.03)\end{array}$ & $\begin{array}{c}5.96(1.22- \\
11.38)\end{array}$ & $\begin{array}{c}1.04(0.63- \\
1.72)\end{array}$ & $\begin{array}{c}9.19(5.96- \\
11.58)\end{array}$ & $\begin{array}{l}35.72(26.73- \\
50.44)\end{array}$ \\
\hline $\mathrm{D}$ & $\begin{array}{c}1.81(1.22- \\
3.37)\end{array}$ & $\begin{array}{l}4.31(3.48- \\
5.36)\end{array}$ & $\begin{array}{c}15.85(8.78- \\
33.65)\end{array}$ & $\begin{array}{l}2.23(1.70- \\
2.86)\end{array}$ & $\begin{array}{c}16.60(13.75- \\
22.99)\end{array}$ & $\begin{array}{c}68.93(51.56- \\
89.53)\end{array}$ \\
\hline $\mathrm{E}$ & $\begin{array}{c}1.95(0.77- \\
3.04)\end{array}$ & $\begin{array}{c}3.96(2.86- \\
5.31)\end{array}$ & $\begin{array}{c}20.46(6.28- \\
29.58)\end{array}$ & $\begin{array}{l}2.12(1.54- \\
2.95)\end{array}$ & $\begin{array}{c}11.79(9.27- \\
20.07)\end{array}$ & $\begin{array}{c}61.58(46.84- \\
81.37)\end{array}$ \\
\hline
\end{tabular}

Data is presented as median (IQR). All hormones increased linearly with breast maturation, $\mathrm{p}<0.001$. To convert E2 to SI units (pmol/L), multiply by 3.67 ; for $\mathrm{E} 1$ (pmol/L), multiply by 3.69 ; for $\mathrm{AD}(\mathrm{nmol} / \mathrm{L})$, multiply by 0.0349 ; for TT (nmol/L), multiply by 0.0347 . 